\title{
Height, weight, and alcohol consumption in relation to the risk of colorectal cancer in Japan: a prospective study
}

\author{
N Shimizu*,', C Nagata', H Shimizu', M Kametani ${ }^{2}$, N Takeyama ${ }^{3}$, T Ohnuma ${ }^{3}$ and S Matsushita ${ }^{2}$ \\ 'Department of Epidemiology and Preventive Medicine, Gifu University School of Medicine, 40 Tsukasa-machi, Gifu 500-8705, Japan; ${ }^{2}$ Department of \\ Internal Medicine, Takayama Red Cross Hospital, 3-II Tenma-cho, Takayama 506-8550, Japan; ${ }^{3}$ Department of Internal Medicine, Takayama Kumiai \\ Hospital, 5-68 Ojin-machi, Takayama 506-8502, Japan
}

\begin{abstract}
Colorectal cancer incidence in relation to body size, smoking, and alcohol consumption was studied in a cohort of $2905 \mathrm{I}$ city residents of Japan. In 1992, each participant completed a self-administered questionnaire on sociodemographic characteristics, drinking, cigarette smoking, diet, exercise, and reproductive and medical histories. The response rate was $92 \%$. From 1993 to 2000, 161 men and 134 women were diagnosed with colorectal cancer at two major hospitals in the city. Relative risks and $95 \%$ confidence intervals were calculated by using Cox proportional hazard models. A positive relation between height and colorectal cancer was seen in both sexes, controlling for age, body mass index (BMI), smoking and drinking habits, and years of education. The findings were statistically significant only for men (relative risk 2.13 for the tallest compared with the shortest height tertile; $95 \%$ confidence interval = 1.26-3.58). Body mass index was also associated positively with colon cancer risk for men, whereas the pattern for women was not clear. There was a positive association between pack-years of cigarette smoking and the risk of rectal cancer in men. $A$ positive dose-response relation between alcohol consumption and colon cancer risk was observed for men and women. British Journal of Cancer (2003) 88, 1038 - 1043. doi:I0.I038/sj.bjc.6600845 www.bjcancer.com (C) 2003 Cancer Research UK
\end{abstract}

Keywords: colorectal cancer; height; body mass; Japanese

Colorectal cancer has become the third leading cause of cancerrelated mortality in Japan (Ministry of Health, Labor and Welfare, 1999), and its incidence has been increasing more rapidly than in other industrialised countries for several decades (WCRF, AIRC, 1997). This appears to be related to lifestyle changes, such as, for example, diet.

Body size, as well as diet, has been investigated in relation to the occurrence of the cancer. Height is affected not only by genetic factors, but also by nutritional condition during childhood and adolescent. Some studies (Albanes et al, 1988; Chute et al, 1991; Bostick et al, 1994; Giovannucci et al, 1995; Robsahm and Tretli, 1999; Smith et al, 2000), but not all (Okasha et al, 2000), have reported a positive association between height and colon cancer. Results of studies on body mass index (BMI) in relation to colorectal cancer have been also inconsistent. There are relatively few prospective studies of colorectal cancer among Japanese (Nomura et al, 1985; Kono et al, 1987; Hirayama, 1989; Akiba, 1994), and only Nomura et al (1985) investigated BMI, which was positively associated with an increased risk for colon cancer among Japanese male immigrants to Hawaii. We have therefore conducted a prospective study, among Japanese people, of colorectal cancer in relation to height, BMI, alcohol consumption, and smoking habit.

\footnotetext{
*Correspondence: Dr N Shimizu; E-mail: g2103006@guedu.cc.gifu-u.ac.jp Received 8 October 2002; revised 30 December 2002; accepted 10 January 2003
}

\section{MATERIALS AND METHODS}

A cohort was established in September 1992 with residents in Takayama, Japan, who were 35 years old or older (Shimizu, 1996). A self-administered questionnaire covering sociodemographic characteristics, drinking, smoking, diet, exercise, and reproductive and medical histories was distributed to 36990 residents, of whom $34018(92.0 \%)$ responded. Subjects who left four out of nine twopage spreads of questionnaire or more all blank $(n=595,1.7 \%)$, and those who inadequately reported to the questionnaire ( $n=1871,5.5 \%)$ were excluded from the cohort. The fixed cohort consisting of 31152 subjects was defined.

The 1992 questionnaire sought details of current height, weight, and weight at age 21 years. The intraclass correlation coefficients between self-reported and measured height and weight in a subsample were 0.93 and 0.97 in both sexes, respectively.

Diet was assessed by a semiquantitative food-frequency questionnaire that contained 169 food items, covering average consumption frequencies and serving sizes of selected food items during the previous year. Individual nutrient intake was estimated based upon the frequency of intake and portion size using the Standard Tables of Food Composition in Japan, 5th edition, published by the Science and Technology Agency of Japan. Details including results of validity tests are described elsewhere (Shimizu et al, 1999).

The questions on alcohol use included six types, that is, sake, beer, light beer, shochu (distilled from sweet potatoes, rice, or buckwheat), wine, and hard liquor. For each item, the questionnaire included nine frequency categories (never/less than once a month; once a month; twice or three times a month; once a week; twice or three times a week; four to six times a week; once a day; 
twice a day; more than four times a day) and the number of cups, glasses, and bottles consumed. The amount of ethanol was calculated in grams using the Standard Tables mentioned above. The correlation coefficients that compare alcohol consumption estimated from the questionnaire with 12 one-day diet diaries at about 1 -month intervals over 1 year were 0.72 and 0.64 , for men and women, respectively (data not published).

Years of smoking and the number of cigarettes smoked each day were reported. Those who had smoked a total of 20 or more packs of cigarettes in their lifetime were defined as smokers.

Physical activity was based on average hours per week spent performing various kinds of activities; details, including the results of the validity tests, are described elsewhere (Suzuki et al, 1998; Shimizu, 2001).

Participants who did not report their height (564 men, 709 women) were excluded from the study, as were those who reported cancer other than nonmelanoma skin cancer (173 men, 532 women) or colorectal adenoma (281 men, 208 women) at baseline. We could not obtain information about diagnosis for 13 men and 15 women who were known to have died of colorectal cancer; thus, these men and women were also excluded from the analysis. The subjects totalled 29051(13392 men and 15659 women).

There were 198 (105 men, 93 women) with colon and 97 (56 men, 41 women) with rectal cancer, all diagnosed histologically at two major hospitals in Takayama City during the follow-up from 1 January 1993 to 31 December 2000. Compared to the number of colorectal cancer occurred in the city according to the annual reports issued by the prefecture government (Hida Public Health Center, 2000 ), the two hospitals covered about $90 \%$ of colorectal cancers in the city each year. Details of subjects who moved away from the city during the study period were obtained from the residential registers, namely, $629(4.7 \%)$ men and 508 (3.2\%) women.

We analysed height, BMI, and smoking and drinking habits in relation to colorectal cancer risk with a separate analysis for colon and rectal cancers. Individuals were categorised into tertiles according to the distribution of height and BMI. Variables for smoking and drinking were categorised, and tests for a linear trend were performed on ordinal variables or continuous variables with the use of median values of the category. Person-years were accumulated up to death, loss to follow-up or the end of 2000, whichever occurred first. Cox proportional hazard models were used to calculate hazard ratios. All reported $P$-values were two sided. In all proportional hazard models, adjustments were made for age, and, where indicated in the text and tables, for other known risk factors. All statistical analyses were performed using PC-SAS (SAS Institute, SAS/STAT user's guide, Version 8.2, SAS Institute, Cary, NC, USA).

\section{RESULTS}

The mean ages (standard deviations) of participants were 54.1 (12.2) for men and 55.1 (13.0) for women. The average heights of each age strata were comparable to those of the general population in Japan. The distribution of various factors possibly related to colorectal cancer by height and sex is shown in Table 1. Age varied inversely with height. The percentages of ever-smokers and persons with higher education increased across the strata of height. Taller men and women consumed more calories and were more physically active. The incidence rates in this cohort by age strata were comparable to those in the general population in Japan (The Research Group for Population-based Cancer Registration in Japan, 2002).

Positive relations between height and colon cancer are seen for men, but were weaker and nonsignificant for women (Table 2). For men, the relative risks (RRs) of colon cancer from the shortest to the middle and tallest height categories were 1.75 (95\% confidence interval, $\mathrm{CI}=1.07-2.85)$ and $2.13(95 \% \mathrm{CI}=1.26-3.58)$, respectively, with a $P$ for trend of 0.004 , after controlling for age, BMI, alcohol consumption, smoking, and education. For women, the point estimates of colon cancer risk for the middle and the tallest categories of height were moderately but not significantly elevated. Further adjustments for physical activity did not substantially alter the results (RRs of colon cancer for the tallest height tertile compared with the shortest tertile adjusted for age, BMI, alcohol consumption, smoking, education, and physical activity $=2.07$ $(95 \% \mathrm{CI}=1.21-3.52)$ and $1.56(95 \% \mathrm{CI}=0.85-2.88)$, for men and women, respectively). We further performed adjustments for nutrient intake, such as total energy and dietary fibre. The results were not modified by the adjustments.

Table 3 shows that BMI was positively associated with the risk of colon cancer for men, whereas the association for women was weak, controlling for age, height, alcohol consumption, smoking, and education. There was no significant association between height and the risk of rectal cancer in both sexes. Further adjustment for physical activity did not substantially alter the results. Our additional analysis for BMI calculated using selfreported weight at age 21 years did not demonstrate any associations or trends (data not shown).

Table I Distribution of various factors by sex and height

\begin{tabular}{|c|c|c|c|c|c|c|}
\hline & \multicolumn{6}{|c|}{ Height $(\mathrm{cm})$} \\
\hline & \multicolumn{3}{|c|}{ Men } & \multicolumn{3}{|c|}{ Women } \\
\hline & $\begin{array}{l}\text { Short } \\
\leqslant 162\end{array}$ & $\begin{array}{l}\text { Medium } \\
163-167\end{array}$ & $\begin{array}{l}\text { Tall } \\
\geqslant 168\end{array}$ & $\begin{array}{l}\text { Short } \\
\leqslant 150\end{array}$ & $\begin{array}{l}\text { Medium } \\
|5|-\mid 54\end{array}$ & $\begin{array}{l}\text { Tall } \\
\geqslant 155\end{array}$ \\
\hline Number & 4863 & 3932 & 4597 & 6393 & 3643 & 5623 \\
\hline Age $(\text { years })^{a}$ & $60.2(11.9)$ & $53.8(11.0)$ & $48.0(10.0)$ & $61.9(13.0)$ & $53.2(10.9)$ & $48.8(10.4)$ \\
\hline Height $(\mathrm{cm})^{\mathrm{a}}$ & $157.5(4.4 \mid)$ & $164.9(1.37)$ & $171.7(3.46)$ & $\mid 46.0(4.5 \mid)$ & $152.6(1.03)$ & $158.3(3.12)$ \\
\hline Weight $(\mathrm{kg})^{\mathrm{a}}$ & $55.4(7.43)$ & $61.1(7.46)$ & $67.1(8.80)$ & $47.1(6.99)$ & $51.4(6.58)$ & $54.7(7.12)$ \\
\hline Body mass index $\left(\mathrm{kg} \mathrm{m}^{-2}\right)^{\mathrm{a}}$ & $22.3(2.87)$ & $22.5(2.72)$ & $22.7(2.79)$ & $22.1(3.14)$ & $22.1(2.80)$ & $21.8(2.76)$ \\
\hline Diabetes mellitus (\%) & 7.1 & 6.5 & 5.0 & 3.6 & 2.7 & 1.8 \\
\hline Cholecystectomy (\%) & 1.2 & 0.7 & 0.7 & 1.2 & 1.5 & 0.8 \\
\hline Education $<12$ years (\%) & 74.9 & 56.7 & 61.4 & 83.1 & 64.2 & 48.4 \\
\hline $\begin{array}{l}\text { Physical activity score } \\
\quad\left(\text { METs }^{\mathrm{b}} \text { - hour week }\right. \\
\text {-1 })^{\mathrm{a}}\end{array}$ & $26.5(40.0)$ & $27.8(41.5)$ & $29.4(44.2)$ & I $6.8(28.1)$ & $20.7(30.4)$ & $22.6(32.0)$ \\
\hline Total energy intake $\left(\mathrm{kcal}^{\text {day }}{ }^{-1}\right)^{\mathrm{a}}$ & 2468 (839) & $2610(874)$ & $2723(880)$ & $2006(761)$ & $2169(789)$ & $2230(576)$ \\
\hline Alchol intake $\left(\text { g day }^{-1}\right)^{a}$ & $36.9(38.7)$ & $42.7(41.9)$ & $44.7(42.8)$ & $6.18(14.2)$ & $7.48(16.3)$ & $9.54(19.3)$ \\
\hline Ever-smokers (\%) & 81.5 & 83.2 & 85.2 & 14.6 & 16.5 & 20.8 \\
\hline
\end{tabular}

${ }^{a}$ Values are means (s.d.). ${ }^{b}$ METs=metabolic equivalents. 
Table 2 Relative risks for colorectal cancer according to height

Men, height $(\mathrm{cm})$

\begin{tabular}{|c|c|c|c|c|}
\hline & Low, $\leqslant 162$ & Medium, $163-167$ & High, $\geqslant 168$ & $P$ for trend \\
\hline \multicolumn{5}{|l|}{ Colon cancer } \\
\hline Person-years & 36584 & 30108 & 35315 & \\
\hline Age-adjusted RRs (95\% Cl) & 1.00 & $1.73(1.08-2.78)$ & $2.09(1.26-3.46)$ & 0.003 \\
\hline Multivariate RRs $(95 \% \mathrm{Cl})$ & 1.00 & $1.75(1.07-2.85)$ & $2.13(1.26-3.58)$ & 0.004 \\
\hline \multicolumn{5}{|l|}{ Rectal cancer } \\
\hline \multirow[t]{3}{*}{ Multivariate RRs $(95 \% \mathrm{Cl})$} & 1.00 & $1.87(1.02-3.44)$ & $1.21(0.57-2.61)$ & 0.37 \\
\hline & \multicolumn{4}{|c|}{ Women, height $(\mathrm{cm})$} \\
\hline & Low, $\leqslant 150$ & Medium, I5I-I54 & High, $\geqslant 155$ & $P$ for trend \\
\hline \multicolumn{5}{|l|}{ Colon cancer } \\
\hline \multicolumn{5}{|l|}{ Rectal cancer } \\
\hline Person-years & 43658 & 25588 & 39596 & \\
\hline Number & 19 & 10 & 12 & \\
\hline Age-adjusted RRs $(95 \%$ Cl) & 1.00 & $1.10(0.49-2.45)$ & $1.15(0.51-2.59)$ & 0.74 \\
\hline Multivariate RRs $(95 \% \mathrm{Cl})$ & 1.00 & $1.27(0.53-3.06)$ & $1.30(0.52-3.21)$ & 0.56 \\
\hline
\end{tabular}

Multivariate=age, BMl, alcohol consumption, smoking, and years of education. $\mathrm{Cl}=$ confidence interval.

Table 3 Relative risks for colorectal cancer according to BMI

Men, BMI $\left(\mathrm{kg} \mathrm{m}^{-2}\right)$

\begin{tabular}{|c|c|c|c|}
\hline$\leqslant 21.2$ & $21.3-22.4$ & $\geqslant 23.6$ & $P$ for tren \\
\hline 32685 & 33839 & 33772 & \\
\hline 26 & 35 & 43 & \\
\hline 1.00 & $1.47(0.88-2.44)$ & $1.98(1.21-3.25)$ & 0.007 \\
\hline 1.00 & $1.46(0.87-2.46)$ & $2.07(1.26-3.42)$ & 0.004 \\
\hline 1.00 & $1.57(0.92-2.68)$ & $2.11(1.26-3.53)$ & 0.005 \\
\hline 32669 & 33687 & 33728 & \\
\hline 24 & 18 & 16 & \\
\hline 1.00 & $0.85(0.46-1.56)$ & $0.85(0.45-1.60)$ & 0.60 \\
\hline 1.00 & $0.76(0.40-1.44)$ & $0.79(0.41-1.52)$ & 0.47 \\
\hline 1.00 & $0.80(0.41-1.55)$ & $0.83(0.42-1.64)$ & 0.59 \\
\hline \multicolumn{4}{|c|}{ Women, BMI $\left(\mathrm{kg} \mathrm{m}^{-2}\right)$} \\
\hline
\end{tabular}

Colon cancer
Person-years
Number
Age-adjusted RRs $(95 \% \mathrm{Cl})$
Multivariate RRs $(\mathrm{I})(95 \% \mathrm{Cl})$
Multivariate RRs $(2)(95 \% \mathrm{Cl})$
Rectal cancer
Person-years
Number
Age-adjusted RRs $(95 \% \mathrm{Cl})$
Multivariate RRs $(1)(95 \% \mathrm{Cl})$
Multivariate RRs $(2)(95 \% \mathrm{Cl})$

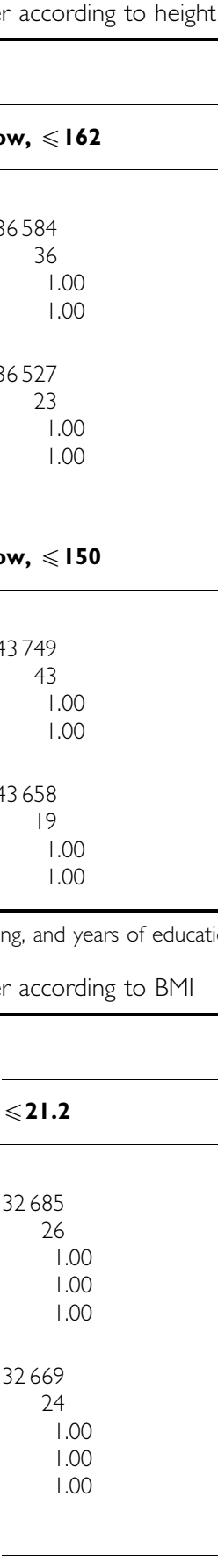

\section{$\leqslant 21.6$}

21.7-23.0

$\geqslant 23.1$

$P$ for trend
Colon cancer
Person-years
Number
Age-adjusted RRs $(95 \% \mathrm{Cl})$
Multivariate RRs ( I) $(95 \% \mathrm{Cl})$
Multivariate RRs (2) $(95 \% \mathrm{Cl})$
Rectal cancer

35100
28
1.00
1.00
1.00
35905
25
$1.06(0.61-1.82)$
$1.08(0.58-2.00)$
$1.02(0.55-1.91)$

1.00
1.00

36373
36
$1.14(0.68-1.90)$
$1.26(0.72-2.22)$
$1.22(0.69-2.15)$

$\begin{array}{lcc}\text { Person-years } & 25046 & 35836 \\ \text { Number } & 14 & 12 \\ \text { Age-adjusted RRs }(95 \% \mathrm{Cl}) & 1.00 & 0.77(0.35-1.7 \mathrm{l}) \\ \text { Multivariate RRs }(1)(95 \% \mathrm{Cl}) & 1.00 & 0.86(0.36-2.02) \\ \text { Multivariate RRs }(2)(95 \% \mathrm{Cl}) & 1.00 & 0.84(0.36-1.99)\end{array}$

36290

15

$0.92(0.44-1.92) \quad 0.86$

$0.98(0.44-2.20) \quad 0.99$

$0.83(0.35-1.99) \quad 0.68$

Multivariate ( 1 )=adjusted for age, height, alcohol consumption, smoking, and years of education. Multivariate (2)=adjusted for age, height, alcohol consumption, smoking, years of education, and physical activity. $\mathrm{Cl}=$ confidence interval. 
The associations between total alcohol intake and colorectal cancer are shown in Table 4. Relative risks of colon cancer for individuals in the highest alcohol consumption compared with abstainers were $2.52(95 \% \quad \mathrm{CI}=1.00-6.38)$ and $1.73 \quad(95 \%$ $\mathrm{CI}=0.98-3.05)$ for men and women, respectively, controlling for age, height, BMI, smoking, and education. However, a significant positive relation with rectal cancer risk was restricted to women. In the analysis by type of beverage, sake consumption was significantly associated with colon cancer risk in men (the RR from the abstainers to the highest sake consumption category $=1.91 ; 95 \% \mathrm{CI}=1.10-3.32$ ).

Men smoked more than 20 pack-years of cigarettes were associated with elevated rectal cancer risk (Table 5). No pattern of changing risk was observed in women who smoked more than 10 pack-years.

\section{DISCUSSION}

These data indicated that being tall or overweight is associated with an increased risk of colon cancer in men, while alcohol consumption was associated with colon cancer risk in both sexes.

Six other prospective studies (Albanes et al, 1988; Chute et al, 1991; Bostick et al, 1994; Giovannucci et al, 1995; Robsahm and Tretli, 1999; Smith et al, 2000), but not all, support our finding that being tall significantly elevates the risk of colorectal cancer. One possibility is that taller people may have longer intestines (Hirsch et al, 1956) and have a greater rate of cell division within the tissue (Albanes and Winick, 1988); thus, more colon cells may be at risk. Greater exposure to mitogenic factors, such as growth hormone, insulin, insulin-like growth factors, and sex steroids, could also result in increased cancer risk. Height has been related to elevated risk of several specific cancers, including breast (Swanson et al, 1988) and prostate (Smith et al, 2000). Animal experiments have shown that low-energy diets from early age shorten overall animal length and reduce cancer risk (Kritchevsky, 1995). In humans, wartime food deprivation for pubescent women was associated with lower breast cancer rates than in younger and older cohorts (Tretli and Gaard, 1996). Furthermore, an association has been reported between higher caloric intake during childhood and higher rates of cancer (Frankel et al, 1998). Height is partly determined by total caloric intake during childhood and adolescence; so its association with colon cancer may indicate that total caloric intake during childhood is relevant for a later colon cancer risk.

Evidence has long suggested that people with excess body weight are at higher risk of colorectal cancer (Lew and Garfinkel, 1979; Nomura et al, 1985; Albanes and Taylor, 1990). Our study, as well as others (Garfinkel, 1985; Wu et al, 1987; Russo et al, 1998; Robsahm and Tretli, 1999; Murphy et al, 2000), shows a positive association between the risk of colon cancer of BMI in men but not in women. Other case-control studies (Slattery et al, 1997; Caan et al, 1998) and a cohort study (Ford, 1999) have shown a significant positive association between the risk of colon cancer and BMI in both sexes, although this was weaker among women in the two case-control studies. Central obesity, which may increase colon cancer risk by acting as a tumour-growth promoter or mitogen (Giovannucci, 1995; Bjorntorp, 1991), is more common among males. Thus, BMI may simply be a more accurate indicator of central obesity for men than for women (Murphy et al, 2000). Another possibility is a protective effect of oestrogen.

Our study also shows a significant positive dose-response relation between alcohol consumption and colon cancer risk in both sexes, although not significant in women as found in other studies. In a prospective study in California, the RR of colorectal cancer was $2.42(95 \% \mathrm{CI}=1.3-4.5)$ in men who drank more than $30 \mathrm{ml} \mathrm{day}^{-1}$ compared to nondaily alcohol drinkers, while the RR among women who consumed more than $30 \mathrm{ml} \mathrm{day}^{-1}$ relative to the same group was weaker and not significant $(R R=1.45$, $\mathrm{CI}=0.8-2.6)$ (Wu et al, 1987). Similar results were obtained when the cases of rectal cancer were omitted. Klatsky et al (1988) prospectively studied and found a positive relation between the

Table 4 Relative risks for colorectal cancer according to alcohol consumption

Men, alcohol intake

\begin{tabular}{|c|c|c|c|c|}
\hline & & & & \\
\hline & No alcohol & $\leqslant 36.7$ g day $^{-1}$ & $>36.7 \mathrm{~g} \mathrm{day}^{-1}$ & $P$ for trend \\
\hline \multicolumn{5}{|l|}{ Colon cancer } \\
\hline Person-years & 8088 & 46494 & 47424 & \\
\hline Cases, $n$ & 5 & 45 & 58 & \\
\hline Age-adjusted RRs (Cl) & 1.00 & $1.94(0.77-4.90)$ & $2.96(1.17-7.46)$ & 0.007 \\
\hline Multivariate RRs $(\mathrm{Cl})$ & 1.00 & $1.79(0.7 \mid-4.55)$ & $2.67(1.06-6.76)$ & 0.01 \\
\hline \multicolumn{5}{|l|}{ Rectal cancer } \\
\hline Person-years & 8114 & 46379 & 47289 & \\
\hline Cases, $n$ & 8 & 20 & 31 & \\
\hline Age-adjusted RRs (Cl) & 1.00 & $0.57(0.25-1.30)$ & $1.12(0.50-2.51)$ & 0.06 \\
\hline \multirow[t]{3}{*}{ Multivariate RRs $(\mathrm{Cl})$} & 1.00 & $0.59(0.25-1.42)$ & $1.17(0.50-2.73)$ & 0.06 \\
\hline & \multicolumn{4}{|c|}{ Women, alcohol intake } \\
\hline & No alcohol & $\leqslant 3.75 \mathrm{~g} \mathrm{day}^{-1}$ & $>3.75 \mathrm{~g} \mathrm{day}^{-1}$ & $P$ for trend \\
\hline \multicolumn{5}{|l|}{ Colon cancer } \\
\hline Person-years & 36265 & 36394 & 36416 & \\
\hline Cases, $n$ & 34 & 28 & 32 & \\
\hline Age-adjusted RRs (Cl) & 1.00 & $0.87(0.5 \mid-1.49)$ & $1.52(0.92-2.53)$ & 0.04 \\
\hline Multivariate RRs $(\mathrm{Cl})$ & 1.00 & $1.07(0.58-1.96)$ & $1.78(1.00-3.18)$ & 0.03 \\
\hline \multicolumn{5}{|l|}{ Rectal cancer } \\
\hline Person-years & $36|3|$ & 36325 & 36385 & \\
\hline Cases, $n$ & 7 & 15 & 19 & \\
\hline Age-adjusted RRs (Cl) & 1.00 & $1.88(0.74-4.79)$ & $2.27(0.9 \mid-5.69)$ & 0.17 \\
\hline Multivariate RRs $(\mathrm{Cl})$ & 1.00 & $1.20(0.44-3.26)$ & $1.80(0.70-4.62)$ & 0.17 \\
\hline
\end{tabular}

Multivariate=adjusted for age, height, BMI, smoking, and years of education. 
Men, smoking status

\begin{tabular}{|c|c|c|c|c|}
\hline & \\
\hline & Never smoked & Smokers $\leqslant 20$ pack-years & Smokers $>20$ pack-years & $P$ for trend \\
\hline \multicolumn{5}{|l|}{ Colon cancer } \\
\hline Person-years & 16702 & $42|4|$ & 37361 & \\
\hline Cases, $n$ & 16 & 41 & 47 & \\
\hline Age-adjusted RRs (Cl) & 1.00 & $1.33(0.78-2.28)$ & $1.43(0.85-2.41)$ & 0.09 \\
\hline Multivariate RRs $(\mathrm{Cl})$ & 1.00 & $1.36(0.79-2.33)$ & $1.37(0.8 \mid-2.32)$ & 0.19 \\
\hline \multicolumn{5}{|l|}{ Rectal cancer } \\
\hline Person-years & 16653 & 42009 & 37327 & \\
\hline Cases, $n$ & 7 & 16 & 34 & \\
\hline Age-adjusted RRs (Cl) & 1.00 & $1.22(0.54-2.78)$ & $2.36(1.13-4.92)$ & 0.03 \\
\hline \multirow[t]{3}{*}{ Multivariate RRs $(\mathrm{Cl})$} & 1.00 & $1.33(0.57-3.12)$ & $2.44(1.12-5.30)$ & 0.04 \\
\hline & \multicolumn{4}{|c|}{ Women, smoking status } \\
\hline & Never smoked & Smokers $\leqslant 10$ pack-years & Smokers > 10 pack-years & $P$ for trend \\
\hline \multicolumn{5}{|l|}{ Colon cancer } \\
\hline Person-years & 82430 & 8944 & 7273 & \\
\hline Cases, $n$ & 68 & 4 & 5 & \\
\hline Age-adjusted RRs (Cl) & 1.00 & $0.65(0.24-1.76)$ & $0.97(0.39-2.40)$ & 0.91 \\
\hline Multivariate RRs $(\mathrm{Cl})$ & 1.00 & $0.59(0.21-1.62)$ & $0.77(0.30-1.96)$ & 0.54 \\
\hline \multicolumn{5}{|l|}{ Rectal cancer } \\
\hline Person-years & 82266 & 8944 & 7264 & \\
\hline Cases, $n$ & 32 & 4 & 2 & \\
\hline Age-adjusted RRs (Cl) & 1.00 & $1.69(0.59-4.86)$ & $1.06(0.25-4.47)$ & 0.47 \\
\hline Multivariate RRs $(\mathrm{Cl})$ & 1.00 & $1.76(0.60-5.14)$ & $0.94(0.21-4.16)$ & 0.63 \\
\hline
\end{tabular}

Multivariate=adjusted for age, height, BMI, alcohol intake, and years of education.

risk of colon cancer and total alcohol intake in both sexes, although the results in women but not men were statistically significant. On the other hand, a meta-analysis (Longnecker et al, 1990) including both prospective and case-control studies showed that the RR of colorectal cancer was $1.10(95 \% \mathrm{CI}=1.05-1.14)$, and the association did not vary according to gender or site within the large bowel. In almost all case-control studies, the use of hospital controls, among which proportions of alcohol-related disease were high, may have biased the results.

There was no association between BMI and rectal cancer risk in both the sexes. Similar finding was obtained in a case-control study reported by Dietz et al (1995), that body weight was positively associated with colon cancer but not with rectal cancer. Positive association between BMI and rectal cancer has been reported in some studies (Phillips and Snowdon, 1985; Russo et al, 1998), but not in others (Dietz et al, 1995; Howe et al, 1997). A significant association between alcohol consumption and rectal cancer risk has been reported (Klatsky et al, 1988; Hirayama, 1989), but in our study, the association was weak in men. We must mention that the number of cases of rectal cancer might be too small to have meaningful analyses.

Recent prospective studies have suggested a positive association between long-term and heavy smoking and colon cancer (Giovannucci et al, 1994; Hsing et al, 1998; Terry et al, 2001). In our present study, no significant association was observed in relation to the quantity of cigarettes smoked except for rectal cancer risk in men.

A major advantage of our study is that it is population based and prospective, thereby minimising recall bias. Incidence rather than mortality can avoid bias because of a progress of medical treatment as well as effect of disease. Furthermore, the data were analysed adjusting for physical activity, nutrition, and years of education.

However, several limitations must be considered. Firstly, height was self-reported and not measured. Although the intraclass correlation coefficient between self-reported height and measured height in a subsample was relatively high, self-reported information may result in misclassification. However, since the height information was collected before the development of cancer, any misclassification would be nondifferential with respect to the disease. Such random misclassification would tend to attenuate RR estimates, and, thus, would not explain the association between height and colon cancer.

Secondly, height was reported at the baseline. Stature has been reported to be at its peak at the end of the third decade of life (Friedlander et al, 1977). Our subjects were 35 years old or over, so their height at the baseline might have been already reduced by ageing or disease and may not have represented their highest. However, age was adjusted for in our analysis, while additional adjustment for pre-existing disease, such as hypertension and diabetes mellitus, did not substantially alter the results.

Another limitation is incomplete detection of colorectal cancers, although details from the two study hospitals appear to cover around $90 \%$ of the colorectal cancers in the city reported by the prefectural cancer registry. Some colorectal cancer patients must therefore have been classified as subjects without colorectal cancer. However, it is unlikely that taller or heavier patients were selectively included in the present study. In addition, the study was so large that the effect of misclassification of true cases was minimal.

In summary, this cohort study provides evidence that height and overweight may be associated with an increased risk of colon cancer for Japanese men, and heavy alcohol consumption may increase the risk of colon cancer in both sexes.

\section{ACKNOWLEDGEMENT}

We thank the Ministry of Education, Culture, Science, and Technology, Japan, for its partial financial support of this project. 


\section{REFERENCES}

Albanes D, Jones DY, Schatzkin A, Micozzi MS, Taylor PR (1988) Adult stature and risk of cancer. Cancer Res 48: $1658-1662$

Albanes D, Taylor PR (1990) International differences in height and weight and their relationship to cancer incidence. Nutr Cancer 14: 69-77

Albanes D, Winick M (1988) Are cell number and cell proliferation risk factors for cancer? J Natl Cancer Inst 80: 772-774

Akiba S (1994) Analysis of cancer risk related to longitudinal information on smoking habits. Environ Health Perspect 102 (Suppl 8): 15-20

Bjorntorp P (1991) Metabolic implications of body fat distribution. Diabetes Care 14(12): 1132-1143

Bostick RM, Potter JD, Kushi LH, Sellers TA, Steinmetz KA, McKenzie DR, Gapstur SM, Folsom AR (1994) Sugar, meat, and fat intake, and nondietary risk factors for colon cancer incidence in Iowa women (United States). Cancer Causes Control 5: 38-52

Caan BJ, Coates AO, Slattery ML, Potter JD, Quesenberry Jr CP, Edwards SM (1998) Body size and the risk of colon cancer in a large case-control study. Int J Obes 22: 178-184

Chute CG, Willet WC, Colditz GA, Stampfer MJ, Baron JA, Rosner B, Speizer FE (1991) A prospective study of body mass, height, and smoking on the risk of colorectal cancer in women. Cancer Causes Control 2: $117-124$

Diez AT, Newcomb PA, Marcus PM, Storer BE (1995) The association of body size and large bowel cancer risk in Wisconsin (United States) women. Cancer Causes Control 6: 30-36

Ford ES (1999) Body mass index and colon cancer in a national sample of adult US men and women. Am J Epidemiol 150(4): 390-398

Frankel S, Gunnell DJ, Peters TJ, Maynard M, Smith GD (1998) Childhood energy intake and adult mortality from cancer: the Boyd Orr Cohort Study. BMJ 316: $499-504$

Friedlander JS, Costa PT, Bosse R, Ellis E, Rhoads JG, Stoudt HW (1977) Longitudinal physique changes among healthy white veterans at Boston. Hum Biol 49: $541-558$

Garfinkel L (1985) Overweight and cancer. Ann Intern Med 103(6): $1034-$ 1036

Giovannucci E (1995) Insulin and colon cancer. Cancer Causes Control 6: $164-179$

Giovannucci E, Ascherio A, Rimm EB, Colditz GA, Stampfer MJ, Willet WC (1995) Physical activity, obesity, and risk for colon cancer and adenoma in men. Ann Intern Med 122: 327-334

Giovannucci E, Rimm EB, Stampfer MJ, Colditz GA, Ascherio A, Kearney J, Willet WC (1994) A prospective study of cigarette smoking and risk of colorectal adenoma and colorectal cancer in US men. J Natl Cancer Inst 86: $183-191$

Hida Public Health Center (2000) Hida no Koushueisei. pp 66-67 Gifu, Japan: Hida Public Health Center (in Japanese)

Hirayama T (1989) Association between alcohol consumption and cancer of the sigmoid colon: observations from a Japanese cohort study. Lancet 2(8665): $725-727$

Hirsch J, Ahrens Jr EH, Blankenhorn DH (1956) Measurement of the human intestinal length in vivo and some causes of variation. Gastroenterology 31: 274-284

Howe GR, Aronson KJ, Benito E, Castello R, Cornee J, Duffy S, Gallagher RP, Iscovich JM, Deng-ao J, Kaaks R, Kune GA, Kune S, Lee HP, Lee M, Miller AB, Peters RK, Potter JD, Riboli E, Slattery ML, Trichopoulos D, Tuyns A, Tzonou A, Watson LF, Whittemore AS, Wu-Williams AH, Shu Z (1997) The relationship between dietary fat intake and risk of colorectal cancer: evidence from the combined analysis of 13 case control studies. Cancer Causes Control 8: 215-228

Hsing AW, Mclaughlin JK, Chow W, Schuman LM, Co Chien HT, Gridley G, Bjelke E, Wacholder S, Blot WJ (1998) Risk factors for colorectal cancer in a prospective study among US White men. Int J Cancer 77: 549-553

Klatsky AL, Armstrong MA, Friedman GD, Hiatt RA (1988) The relations of alcoholic beverage use to colon and rectal cancer. Am J Epidemiol 128(5): $1007-1015$

Kritchevsky D (1995) The effect of over- and undernutrition on cancer. Eur J Cancer Prev 4: $445-451$
Kono S, Ikeda M, Tokudome S, Nishizumi M, Kuratsune M (1987) Cigarette smoking, alcohol and cancer mortality: a cohort study of male Japanese physician. Jpn J Cancer Res 78: $1323-1328$

Lew EA, Garfinkel L (1979) Variations in mortality by weight among 750,000 men and women. J Chronic Dis 32(8): 563-576

Longnecker MP, Orza MJ, Adams ME, Vioque J, Chalmers TC (1990) A meta-analysis of alcoholic beverage consumption in relation to risk of colorectal cancer. Cancer Causes Control 1: 59-68

Ministry of Health, Labor and Welfare (1999) Vital Statistics of Japan 1999 Tokyo, Japan: Ministry of Health, Labor and Welfare

Murphy TK, Calle EE, Rodriguez C, Kahn HS, Thun MJ (2000) Body mass index and colon cancer mortality in a large prospective study. $A m \mathrm{~J}$ Epidemiol 152: $847-854$

Nomura A, Heilbun LK, Stemmermann GN (1985) Body mass index as a predictor of cancer in men. J Natl Cancer Inst 74: 319-323

Okasha M, McCarron P, McEwen J, Smith GD (2000) Height and cancer mortality: results from Glasgow University Student Cohort. Public Health 114: $451-455$

Phillips RL, Snowdon D (1985) Dietary relationships with fatal colorectal cancer among Seventh-Day Adventists. J Natl Cancer Inst 74: $307-317$

Robsahm TE, Tretli S (1999) Height, weight and gastrointestinal cancer: a follow-up study in Norway. Eur J Cancer Prev 8: 105-113

Russo A, Franceschi S, La Vecchia C, Dal Maso L, Montella M, Conti E, Giacosa A, Falcini F, Negri E (1998) Body size and colorectal-cancer risk. Int J Cancer 78: $161-165$

Shimizu H (1996) A Basic Report on Takayama Study. Gifu, Japan: Department of Public Health, Gifu University School of Medicine

Shimizu H (2001) A supplementary comment on "Reliability and validity of a questionnaire for assessment of physical activity in epidemiological studies" published in Journal of Epidemiology, 1998. J Epidemiol 12: 54

Shimizu H, Ohwaki A, Kurisu Y, Takatsuka N, Ido M, Kawakami N, Nagata C, Inaba S (1999) Validity and reproducibility of a quantitative food frequency questionnaire for a cohort study in Japan. Jpn J Clin Oncol 29(1): $38-44$

Slattery ML, Potter J, Caan B, Edwards S, Coates A, Ma K, Berry TD (1997) Energy balance and colon cancer beyond physical activity. Cancer Res 57:75-80

Smith GD, Hart C, Upton M, Hole D, Gillis C, Watt G, Hawthrone V (2000) Height and risk of death among men and women: aetiological implications of associations with cardiorespiratory disease and cancer mortality. J Epidemiol Community Health 54: 97-103

Suzuki I, Kawakami N, Shimizu H (1998) Reliability and validity of a questionnaire for assessment of energy expenditure and physical activity in epidemiological studies. J Epidemiol 8: $152-159$

Swanson CA, Jones DY, Schatzkin A, Brinton LA, Ziegler RG (1988) Breast cancer risk assessed by anthropometry in the NHANES I epidemiological follow-up study. J Cancer Res 48: $5363-5367$

Terry P, Ekbom A, Lichtenstein P, Feychting M, Wolk A (2001) Long-term tobacco smoking and colorectal cancer in a prospective cohort study. Int J Cancer 91: 585-587

The Research Group for Population-based Cancer Registration in Japan (2002) Cancer incidence and incidence rates in Japan in 1997: estimates based on data from 12 population-based cancer registries. Jpn J Clin Oncol 32(8): $318-322$

Tretli S, Gaard M (1996) Life style changes during adolescence and risk of breast cancer: an ecologic study of the effect of World War II in Norway. Cancer Causes Control 7: 507-512

Potter JD (Panel Chair), Washington DC, WCRF, AIRC (1997) Colon, rectum. Food, Nutrition and the Prevention of Cancer: A Global Perspective pp 216-251

Wu AH, Paganini-Hill A, Ross RK, Henderson BE (1987) Alcohol, physical activity and other risk factors for colorectal cancer: a prospective study. Br J Cancer 55: 687-694 